\title{
Peran Public Relations dalam Mengelola Publikasi Program Kemitraan di PT. Telkom Regional I Medan
}

\section{The Role of Publick Relations in Managing Partnership Publication at PT. Telkom Regional I Medan}

\author{
Rizka Fatimah 1)*, Effiati Juliana Hasibuan 2), Novri ${ }^{3)}$ \\ Ilmu Komunikasi, Fakultas Ilmu Sosial dan Ilmu Politik, Universitas Medan Area, Indonesia
}

\begin{abstract}
Abstrak
Peran public relations didalam sebuah perusahaan adalah membangun citra perusahaan dan menjadi jembatan informasi dari perusahaan kepada publiknya. Seorang Public Relations dapat membangun hubungan yang baik dengan publik melalui kegiatan penyebaran informasi seperti publikasi, agar publik dapat berkecukupan dalam menerima informasi mengenai perusahaan. Tujuan dari penelitian ini adalah untuk mengetahui peran public relations dalam mengelola publikasi program kemitraan dan bagaimana peran public relations dalam mempublikasikan berita program kemitraan di PT.Telkom Regional I Medan. Metode penelitian yang digunakan dalam penelitian ini adalah pendekatan kualitatif, jenis riset ini bertujuan untuk membuat deskripsi serta gambaran secara sistematis, faktual dan akurat mengenai fakta-fakta dan sifat-sifat serta hubungan antarfenomena yang diselediki dengan mengumpulkan data lalu dianalisis untuk memperoleh kesimpulan. Penelitian ini dilakukan dengan observasi secara langsung dan wawancara dengan pihak public relations. Dari hasil penelitian ini, dapat dikatakan bahwa peran public relations dalam rangka membangun citra PT.Telkom Regional I secara keseluruhan sudah berjalan cukup baik.
\end{abstract}

Kata Kunci: public relations, publikasi, program kemitraan

\section{Abstract}

The role of public relations in a company is to build the image of the company and a bridge of information from the company to the public. In order for a Public Relations can build a good relationship with the public and so the public can be adequate in receiving information about the company then the need for information dissemination activities called publications. the purpose of this research is to know the role of public relations in managing the publication of partnership programs and how the role of public relations in publishing news partnership program at PT.Telkom Regional I Medan. The research method used in this research is a qualitative approach, this type of research aims to create description and description systematically, factually and accurately about the facts and the nature and relationship between phenomena are investigated by collecting data and then analyzed to obtain conclusions. this research is done by direct observation and interview with public relations parties. from the results of this study, it can be said that the role of public relations in order to build the image of PT.Telkom Regional I as a whole has been running quite well.

Keywords: public relations, publication, partnership program

How to Cite: Fatimah, Rizka. Hasibuan, E.J. \& Novri. (2020). Peran Public Relations dalam Mengelola Publikasi Program Kemitraan di PT. Telkom Regional I Medan. Jurnal Ilmu Pemerintahan, Administrasi Publik, Ilmu Komunikasi (JIPIKOM), 2(2) 2020: 104-109,

*E-mail: rizkafatimah@gmail.com ISSN 2550-1305 (Online)

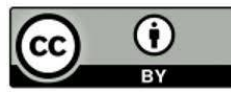




\section{PENDAHULUAN}

Peran public relations didalam sebuah perusahaan sangatlah penting, pada dasarnya peran public relations didalam sebuah perusahaan adalah membangun citra perusahaan dan menjadi jembatan informasi dari perusahaan kepada publiknya. Agar seorang Public Relations dapat membangun hubungan yang baik dengan publik dan agar publik dapat berkecukupan dalam menerima informasi mengenai perusahaan maka perlunya dilakukan kegiatan penyebaran informasi yang dinamakan publikasi.

Publikasi adalah kegiatan memperkenalkan perusahaan kepada publik sehingga publik dapat mengenal perusahaan, baik itu terkait dengan program perusahaan maupun kegiatan yang dilaksanakan. Publikasi biasanya dilakukan dengan kerjasama dengan pihak pers, maka dari itu perlunya menjalin hubungan yang baik dengan pihak pers. Hubungan media dan pers merupakan media kerja sama untuk kepentingan proses publikasi dan publisitas berbagai kegiatan program kerja dan untuk kelancaran aktivitas komunikasi humas dengan pihak publik S(yahputra, D.I. Hendra, Y. \& Hidayat, T.W., 2018.)

PT. Telkom sebagai Badan Usaha Milik Negara melaksanakan kegiatan publikasi yang dimana salah satunya berasal dari program kerja PT.Telkom yaitu Program Kemitraan. Program Kemitraan merupakan program yang dilaksanakan untuk meningkatkan kemampuan pelaku usaha kecil agar menjadi tangguh dan mandiri melalui pemanfaatan dana dari penyisihan laba badan usaha milik negara. Program ini memberikan bantuan berupa pinjaman dana secara bergulir untuk modal kerja bagi pelaku Usaha Mikro dan Kecil. (telkompkbl.com) Karena masih banyaknya masyarakat yang minim pengetahuan dengan program kemitraan maka dari itu Humas PT. Telkom melaksanakan kegiatan publikasi, Agar masyarakat dapat mengetahui perkembangan yang telah dilaksanakan oleh program kemitraan yang biasanya dilakukan publikasi secara berkala setiap 4 kali dalam setahun.

\section{METODE PENELITIAN}

Jenis penelitian ini adalah penelitian yang menggunakan pendekatan kualitatif dengan menggunakan metode penelitian deskriptif kualitatif. Maka untuk memudahkan penjelasan mengenai Peran Public Relations dalam Mengelola Publikasi Program Kemitraan di PT. Telkom Regional I Medan. Peran Public Relations dilihat dari empat aspek yakni: Perencanaan, Pengorganisasian, Pelaksanaan, dan Pengawasan

Lokasi penelitian ini dilakukan di Kota Medan, khususnya di PT.Telkom Regional I. Sumber data yang menjadi fokus penelitian terdiri dari: Sumber data primer yang berupa hasil dari wawancara terhadap informan dan sumber data sekunder yang berupa dokumen-dokumen, arsip-arsip dan kepustakaan. Teknik Pemilihan Informan pada penelitian ini adalah public relations PT.Telkom Regional I Medan dan pihak kemitraan yang ikut bergabung di kemitraan PT.Telkom dan jumlah informan di penelitian ini mengikuti prinsip kejenuhan.

Penelitian ini menggunakan alat instrumen smartphone dan alat rekam suara untuk merekam suara dan mendokumentasikan gambar. Teknik pengumpulan data yang digunakan dalam penelitian ini adalah observasi, wawancara dan dokumentasi. Teknik analisis data yang digunakan dalam penelitian ini adalah pengumpulan data, reduksi data, penyajian data dan penarik kesimpulan. Teknik pemeriksaan keabsahan 
Rizka Fatimah, Effiati Juliana Hasibuan \& Novri, Peran Public Relations dalam Mengelola Publikasi

Program Kemitraan di PT. Telkom Regional I Medan

data di penelitian ini adalah triangulasi meningkatkan ketekunan dan menggunakan bahan referensi.

\section{HASIL DAN PEMBAHASAN}

Peran yang dilakukan public relations PT.Telkom Regional I untuk menciptakan citra positif perusahaan dimata masyarakat dilakukan dengan berbagai upaya, adapun hal yang dilakukan oleh public relations untuk mendapatkan citra yang positif yaitu dengan cara mengelola publikasi program kemitraan yang terdiri dari 4 tahapan yaitu : perencanaan, pelaksanaan, pengorganisasian dan bentuk pengawasan yang dilakukan seorang public relations.

Tujuan dari diadakannya publikasi program kemitraan yaitu untuk menciptakan citra yang positif di mata publiknya. Citra yang positif dapat terbentuk apabila publiknya memiliki persepsi positif mengenai perusahaan tersebut. Dimana persepsi ini harus lengkap dan tidak sepotong-sepotong. Agar hal itu dapat tercapai maka publik harus berkecukupan dalam menerima informasi mengenai perusahaan yang bersangkutan. maka dari itu diperlukannya kegiatan publikasi dalam program kemitraan. Kegiatan dari program kemitraan itu nantinya akan dipublikasikan dengan melakukan kerja sama dengan berbagai media yang ada seperti surat kabar, surat kabar elektronik, online dan berbagai wartawan yang telah dilakukan kerja sama dengan pihak public relations PT.Telkom Regional I sebelumnya.

Setelah melakukan wawancara dengan informan, peneliti memperoleh hasil dari cara pengelolaan publikasi yang terdiri dari 4 tahapan: 1) Perencanaan Public Relations Dalam Mengelola Publikasi. Dalam melakukan sebuah perencanaan public relations melakukan liputan dengan mempelajari rencana kegiatan yang akan dilaksanakan serta mencari data-data awal atau data pendukung dari objek liputan, dalam mempublikasikan berita seorang public relations PT.Telkom Regional I harus mengetahui kegiatan yang akan dipublikasikan terutama dalam program kemitraan apakah berita bisa dipublikasikan kepada masyarakat atau hanya untuk dipublikasikan kepada internal saja.

2) Pengorganisasian Public Relations Dalam Mengelola Publikasi. Tujuan dari pengorganisasian PT.Telkom Regional I yaitu untuk memberikan kemudahan dalam menyelesaikan suatu pekerjaan di dalam sebuah organisasi sehingga pekerjaan dapat terlaksana secara efektif dan sesuai dengan program kerja yang telah ditetapkan.Dalam penelitian ini berbagai upaya yang dilakukan Public relations dalam mengelola publikasi program kemitraan yang terdiri dari pengelolaan, pelaksanaan, perencanaan dan pengawasan yang bertujuan untuk menciptakan citra perusahaan yang positif di mata masyarakat.

3) Pelaksanaan Public Relations Dalam Mengelola Publikasi. Pelaksanaan publikasi program kemitraan bertujuan untuk membuat masyarakat mengetahui kegiatan yang telah dilaksanakan telkom terutama dalam program kemitraan, misalnya dalam hal kegiatan pelaksanaan pameran nasional dengan berbagai sektor industri usaha yang ada dan secara khusus untuk menyampaikan informasi baik dalam media internal maupun eksternal. Tindakan yang dilakukan public relations agar anggota dalam kelompok dapat 
melakukan pelaksanaan kegiatan publikasi program kemitraan sesuai dengan perencanaan yaitu dengan melakukan persiapan secara teknis seperti alat dan waktu yang harus dipersiapkan menjelang acara, media mana yang akan diundang dan untuk pengelolaan media komunikasi public relations berupa website pengelolaannya dipublikasikan oleh regional selanjutnya di distribusikan kepada pusat atau corporate communication.

4) Pengawasan Publikasi Program Kemitraan. Manfaat dari pengawasan publikasi program kemitraan yaitu sebagai langkah perusahaan dalam rangka memonitor setiap informasi dari internal ke eksternal dan tujuannya untuk bisa melihat berita yang sedang hangat diluar perusahaan, khususnya tentang program kemitraan. Sistem pengawasan publikasi yang dilakukan oleh public relations PT.Telkom regional I yaitu: Dengan monitoring media harian media sosial, kliping. biasanya monitoring media dilakukan harian, mingguan bulanan setelah itu diserahkan ke manager, Untuk memperbaiki hasil kerja yang tidak sesuai dengan standar atau tolak ukur Biasanya Public relations PT. Telkom regional I melakukan evaluasi dengan melihat ranking yaitu dengan melihat berapa banyak berita baik dan berita buruk yang diperoleh dalam 1 bulan terakhir, Melihat berapa persen masalah yang berhasil ditangani oleh pihak public relations untuk memperbaiki image perusahaan dan menciptakan citra yang positif dimata masyarakat, Melakukan penanganan terhadap wartawan, dalam mempublikasikan berita PT. Telkom Regional I mempunyai beberapa pos media atau wartawan yang bekerjasama untuk mempublikasikan informasi terutama dalam program kemitraan, Setiap kali mengadakan kegiatan public relations PT.Telkom Regional I mengundang wartawan dari semua channel seperti media online, cetak dan radio dan melakukan gathering setiap 3 bulan sekali dan pihak wartawan dapat menyampaikan keluhan yang terjadi di lapangan dan dari hasil pertemuan dilakukan evaluasi antara hubungan eksternal telkom dengan wartawan.

Jika terjadi berita buruk yang terjadi diluar perkiraan pihak public relations PT.Telkom Regional I melakukan evaluasi dalam lingkungan intenal dan didiskusikan agar bisa menjalankan kegiatan pusat di Regional, dan didalam Regional I memiliki bawahan lagi yang disebut dengan WITEL, WITEL tidak dapat melakukan pergerakan lebih jauh jika tidak ada keputusan dari regional dan regional tidak bisa bergerak jika tidak ada kebijakan dari pusat. Peran yang dilakukan public relations diwujudkan untuk menciptakan citra positif perusahaan secara keseluruhan. yang dimana terbentuk dari banyak hal, seperti riwayat hidup PT.Telkom yang gemilang, keberhasilan public relation PT.Telkom Regional I dalam meraih pemberitaan terbaik di 3 nasional, serta berbagai upaya yang dilakukan dengan membina hubungan yang baik dengan masyarakat. dan menciptakan efek umpan balik antara perusahaan dengan masyarakat, sehingga masyarakat dapat mengetahui informasi dan perkembangan perusahaan berkaitan dengan program kemitraan.

Banyaknya jumlah pegawai (individu), cabang, atau perwakilan dari sebuah perusahaan atau organisasi dapat memunculkan suatu citra yang belum tentu sama dengan citra organisasi atau perusahaan tersebut secara keseluruhan. Maka dalam penelitian ini setelah dilakukan pengumpulan data dengan wawancara terhadap 
informan yang merupakan public relations yang mengelola publikasi program kemitraan diperoleh data dan hasil bahwa peran public relations dalam mengelola publikasi program kemitraan sudah cukup efektif berdasarkan aspek perencanaan, pengorganisasian, pengevalusian dan pengawasan sudah sesuai dengan sasaran kerja individu sehingga pembagian kerja dalam pengelolaan publikasi sudah sesuai dengan SOP perusahaan yang berlaku.

\section{SIMPULAN}

Dalam perencanaan public relations melakukan liputan dengan mendokumentasikan berbagai kegiatan yang dilaksanakan terutama dalam program kemitraan dan dalam melakukan perencaan seorang public relations harus melihat event yang diliputnya apakah event yang diliputnya bisa dipublish secara market di media massa.

Dalam pengorganisasian komitmen pekerjaan seluruh instansi telko $\mathrm{m}$ yang diberikan sudah tertuang dalam Sasaran Kerja Indvidu (SKI) selama satu tahun baik internal maupun eskternal, yang dimana sudah ditandatangani dan dibuat secara online. Dalam pelaksanaan publikasi public relations melakukan persiapan secara teknis seperti alat dan waktu serta menghubungi media mana yang akan diundang, dan untuk pengelolaan berita di publikasikan oleh Regional lalu di distribusikan kepada Pusat sehingga informasi yang dipublikasikan dapat berupa release maupun berita.

Dalam Pengawasan public relations melakukan kliping di media cetak dan memonitor pemberitaan harian, mingguan dan bulanan di media-media yang ada. Untuk melakukan evaluasi public relations melihat berdasarkan ranking dalam satu bulan terakhir, berapa banyak berita yang berhasil di handle dan berapa persen image yang berhasil diperbaiki. Maka Dari hasil penelitian ini, dapat dikatakan bahwa peran public relations dalam rangka membangun citra PT.Telkom Regional I secara keseluruhan sudah berjalan cukup baik.

\section{DAFTAR PUSTAKA}

Abdurrahman, Oemi. (2001). Dasar Dasar Public Relations. Bandung : Citra Aditya Bakti Ahman, Eeng. (2007). Membina Kompetensi Ekonomi. Bandung: Grafindo Media Pratama Amsyah, Zulkifli. (2005). Manajemen Sistem Informasi. Jakarta : PT Gramedia Pustaka Utama Anggoro, M, Linggar. (2002). Teori Dan Profesi Kehumasan Serta Aplikasinya. Jakarta : Bumi Aksara Ardianto, Elvinaro. (2011). Handbook Of Public Relations. Bandung : Simbiosa Rekatama Media Arifin, Imamul, dkk. (2007). Membuka Cakrawala. Ekonomi. Bandung : PT Setia Purna Inves Bisnis Islam, Jurnal Filsafat dan Budaya Hukum.

Bungin, Burhan. (2009). Sosiologi Komunikasi. Jakarta : Kencana

Changara, Hafield. (2008). Pengantar Ilmu Komunikasi. Jakarta : Raja Grafindo Persada

Danandjaja. (2011). Peranan humas dalam perusahaan. Yogyakarta : Graha Ilmu

Dewi, Camelia, Sinta. (2016). Public Relations Telkom Divisi Regional I Sumatera, Medan: PT Telkom Regional I

Effendi, Onong, Uchjana. (1989). Human Relations Dan Public Relations Dalam Manajemen. Bandung : Mandar Maju

Faisal, Rifki, dkk. 2016. Jurnal Ilmu Pertanian dan Peternakan, Vol 4 No. 2.

Gaol, Chr Jimmy L. (2015). Keandalan Dan Sukses Sekretaris Perusahaan Dan Organisasi Jakarta : PT Elex Media Komputindo

Ikatan Bankir Indonesia. 2015. Strategi Bisnis Bank Syariah. Jakarta Pusat: Lembaga Sertifikasi Profesi Perbankan 
Iriantara, Yosal. (2005). Media Relations Konsep Pendekatan Dan Praktik. Bandung : Sembiosa Rekatama Media.

Kartini, Dwi. (2009). Corporate Social Responsibility. Bandung : Refika Aditama

Kristiawan, dkk. (2017). Manajemen Pendidikan. Yogyakarta : CV Budi Utama

Kriyantono, Rachmat. (2010). Teknik Praktis Riset Komunikasi. Jakarta : Prenada Media Group

Kriyantono, Rachmat. (2012). Public Relations Writing. Jakarta : Prenada Media

Lainnya : Telkompkbl.com

Madura, Jeff. (2007). Pengantar Bisnis. Jakarta : Salemba Empat Jakarta

Marno dan Trio Supriyanto. (2008). Manajemen dan Kepemimpinan Pendidikan Islam. Bandung : PT Refika Aditama

Maskur. (2015). Manajemen Humas Pendidikan Islam. Yogyakarta : Deepublish

Morissan. (2008). Manajemen Public Relation. Jakarta: Kencana

Nova, Firsan. (2011). Crisis Public Relations. Jakarta : Rajagrafindo Persada

Oemi, Atiyah. 2007. Profesionalisme Kehumasan, Jurnal Komunika, Vol 10 No.1.

Oliver, Sandra. (2007). Strategi Public Relations. Jakarta : Erlangga

Prastowo, Andi. (2018). Sumber Belajar Dan Pusat Sumber Belajar Teori Dan Aplikasinya Di Sekolah/Madrasah. : Prenamedia Group

Purba, Herdianto. (2009). Great Supervisor. Jakarta: PT Gramedia Pustaka Utama

Rahmawati, Yuki. 2014. Manajemen Public Relations Sebagai Alat Etika Komunikasi Dalam

Rita Silvia Fariani dan Aryanto, Widodo. (2009) Panduan Praktisi Public Relations. Jakarta : Elex Media Kompotindo

Rosady, Ruslan. (2010). Manajemen Public Relations \& Media Komunikasi Konsepsi Dan Aplikasi. Jakarta : Persada

Septiawan, Santana, Kurniawan. (2005). Jurnalisme Kontemporer. Jakarta : Yayasan Obor Indonesia

Sudarso, Andriasan. (2016). Manajemen Pemasaran Jasa Perhotelan. Yogyakarta : Dee Publish

Sugiyono. (2010). Metode Penelitian Kuantitaf kualitatif dan R\&D. Bandung : Alfabeta, Cv

Sukwiaty, dkk. (2006). Ekonomi. Jakarta Timur : Yudhistira

Sunaengsih, Cucun. (2017). Pengelolaan Pendidikan. Sumedang : UPI Sumedang Press

Suparmoko. (2007). Ekonomi. Jakarta : Yudhistira

Syahputra, D.I. Hendra, Y. \& Hidayat, T.W. (2018). Peran Humas Dalam Membangun Citra Pemerintahan Sumatera Utara Pada Kantor Biro Humas Gubernur. PERSPEKTIF, 7 (1): 24-29

Syarifuddin, Aip. 2018. Manajemen Kepemimpinan Organisasi, Jurnal Hadhariyah, Volume 5 No. 2.

Wardhani, Diah. (2008). Media Relations Sarana Membangun Reputasi Organisasi. Yogyakarta : Graha Ilmu

Welsch, Glenn A, dkk. (2000). Anggaran Perencanaan dan Pengendalian Laba. Jakarta : Salemba Empat

Widjaja. (2010). Komunikasi dan Hubungan Masyarakat. Jakarta : Bumi Aksara

Wijaya, S.D., (2016), Studi Korelasi Pemanfaatan Internet Pada Bagian Humas PEMDA Singkil terhadap Peningkatan Kinerja Kehumasan, Jurnal Simbolika: Research and Learning in Comunication Study, 2 (1): $18-27$

Yuliana, Nina. (2014). Media Relations. Yogyakarta : Graha Ilmu 